\title{
Ecos da violência nas margens de uma sociedade democrática: o caso da periferia de Fortaleza
}

\author{
LUIZ FÁBIO S. PAIVA \\ Doutor em Sociologia (Universidade Federal do Ceará) \\ Professor da Universidade Federal do Ceará \\ Fortaleza, Ceará, Brasil \\ luizfabiopaiva@gmail.com
}

Geovani Jacó de Freitas

Doutor em Sociologia (Universidade Federal do Ceará) Professor da Universidade Estadual do Ceará

Fortaleza, Ceará, Brasil giljaco@uol.com.br

\begin{abstract}
Resumo O trabalho é resultado de investigações etnográficas realizadas em bairros localizados na periferia de Fortaleza (CE). Essas investigações tiveram como objetivo compreender os efeitos cotidianos e políticos da violência em territórios urbanos. Observamos que, além da experiência empírica, a violência na periferia pode ser interpretada a partir dos ecos produzidos na vida social de sujeitos que, em tese, deveriam estar resguardados por instâncias constitutivas de uma sociedade democrática de direito. Para isso ser compreendido, procuramos saber como as pessoas interpretam e falam da violência nos bairros em que residem. Encontramos ecos da violência que podem ser percebidos em rumores, medos e separações criadas nas comunidades pesquisadas. Seus efeitos reverberam na maneira como os moradores interpretam suas ações em uma democracia, compartilhando direitos e deveres com pessoas que não se reconhecem como iguais. Em linhas gerais, a cidadania é pensada aqui como um problema moral estruturante da vida na periferia.
\end{abstract}

Palavras-chave: violência; democracia; cidadania; medo; periferia.

S SOCIEDADES DEMOCRÁTICAS representam hoje muito
mais um desafio do que um projeto acabado de vida social. As de-
mocracias como projetos políticos de Estados modernos pacificados pelos
monopólios nacionais da violência ${ }^{1}$ apresentam configurações muito dis-
tintas, desafiando o pensamento social a olhar para o mundo desde as suas
diferenças, e não mais a partir de princípios universais que nunca se efetiva-
ram na prática. Pensar as sociedades democráticas é então um desafio, pois
significa refletir sobre a pluralidade da experiência de regimes políticos que

1 O Estado moderno para Weber (1999) tem como caraterística fundamental a coação física, sendo possível the definir como toda comunidade humana que dentro de determinado território "reclama para si (com êxito) o monopólio da coação física legítima, pois o específico da atualidade é que todas as demais associações ou pessoas individuais somente se atribuem o direito de exercer a coação física na medida em que o Estado o permita" (p. 525-526). 
se construíram em torno das especificidades de comunidades políticas ${ }^{2}$ com características distintas e unidas pelo ideal de uma forma muita específica de governo. Para pensar, no entanto, em elementos que estruturam regimes democráticos, imaginamos que, como destaca O’Donnell (2004), uma democracia se constrói em torno da liberdade para que cidadãos políticos de um Estado ocupem, por meio de eleições livres, as principais posições governamentais, gozando de uma pluralidade de direitos e obrigações compartilhados e protegidos por sistemas legais. Para que ela exista, Tilly (2013) ressalta que o Estado deve ter a capacidade de garantir a participação e implementar suas decisões políticas, realizando a integração de redes de confiança na vida pública. Ambos os autores nos ajudam a considerar as democracias e os processos de democratização como fenômenos históricos e sociais permeados por nuances que devem ser observadas na prática de instauração e manutenção de regimes democráticos.

Outro elemento importante para os Estados democráticos envolve a caracterização e o entendimento coletivo do que significa a cidadania para a vida das pessoas. Rosanvallon (2004) observa que a cidadania, em uma sociedade democrática, se caracteriza pela existência de um mundo em comum, com referências e possibilidades que possam ser compartilhadas pelos seus membros. A democracia não constitui para Rosanvallon apenas um modelo, mas uma experiência social que possui uma historicidade. Assim, ele esclarece que "la vida y la 'calidad' de las democracias, tanto en América Latina como em cualquier outra región, es indisociable de un trabajo de exploración y de experimentación, de comprensión $y$ de elaboración de sí mismas" (Rosanvallon, 2004, p. 196). Não existem respostas simplesmente adequadas aos problemas das democracias, e é preciso estar sempre atento às sensibilidades que compõem as realidades sociais estudadas. Ao considerar esta observação, é preciso levar em conta as peculiaridades relacionadas, entre outras coisas, às dinâmicas do desenvolvimento econômico, da institucionalidade do direito e das correlações de força que afetam a vida social em suas diferentes instâncias de realização. No Brasil, por exemplo, estudiosos apontam para o fato de que a democratização dos direitos políticos não foi acompanhada por possibilidades de acesso ao mercado de trabalho, aos bens de consumo e aos direitos sociais, construindo desigualdades econômicas e sociais que dão uma forma muito especial à nossa "jovem" democracia (Souza, 2012; Caldeira, 2003).
Ao olhar para a sociedade brasileira, considerando os apontamentos apresentados, compreendemos que ela é portadora de peculiaridades muito específicas em relação à democracia e à maneira como pessoas, instituições e organizações da sociedade civil se relacionam e formam as teias de interdependência do Estado-nação no maior país da América Latina. Nesta perspectiva, abordamos a democracia brasileira como uma questão cultural que envolve os relacionamentos entre múltiplas instâncias de organizações sociais constitutivas do Estado brasileiro e permeadas por problemas sociais diversos. Nosso objetivo é refletir sobre como a democracia pode ser desde as margens, os limites e as experiências críticas de pessoas que vivem cotidianos transpassados por situações de violência. Exploramos como os ecos da violência afetam as vidas de pessoas e problemas relacionados ao Estado são vividos no cotidiano de bairros populares. Para explicar como construímos essa reflexão, passamos para algumas considerações teórico-metodológicas referentes às pesquisas que subsidiaram este trabalho.

\section{Considerações teórico-metodológicas sobre a violência em uma sociedade democrática}

Em uma perspectiva antropológica, Holston (2013) salienta que a democracia, em países como o Brasil, não poder ser compreendida tendo como modelo os regimes estadunidenses e europeus sob pena de as peculiaridades nacionais serem reduzidas a prerrogativas de falta e incompletude. É preciso encontrar as especificidades que fazem da democracia uma experiência que ultrapassa a dimensão institucional de como se constituem governos, explorando práticas sociais que envolvem as instâncias de poder e as vivências de sujeitos em suas práticas sociais ${ }^{3}$. Este trabalho se inscreve nessa perspectiva ao abordar questões práticas vividas por pessoas residentes em bairros populares que, no seu dia a dia, experimentam e falam de seus problemas em um Estado democrático de direito. Interessa-nos sobremaneira pensar a democracia à luz do cotidiano, em especial, considerando os problemas relativos ao que conhecemos como violência urbana.

2 Pensamos aqui, também, no conceito de Weber (1999, p. 155-157), cujo fundamento é a relação entre pessoas, em um território, ordenada pela preservação do monopólio da violência e pela crença específica "numa especial sagração, dada pela 'conformidade da lei' da ação social por elas ordenadas".

3 Avritzer e Costa (2004) ressaltaram que os estudos sociológicos sobre os processos de democratização, na década de 1990, evidenciaram a necessidade de análises que ultrapassem as dimensões institucionais para a observação de práticas sociais e culturais de democracias em países como os latino-americanos, refletindo criticamente a respeito das formas de relacionamento entre o Estado, as instituições políticas e a sociedade. 
Em linhas gerais, adotamos aqui a perspectiva de Silva (2008), que trata a violência urbana como uma representação coletiva que não tem um significado homogêneo, mas existe como uma categoria do entendimento do senso comum que consolida e oferece sentido a experiências vividas na cidade. Assim, a violência não é apenas relacionada ao crime, pois tem um horizonte semântico mais amplo e nos permite pensar, entre outras coisas, os problemas políticos e morais que permeiam a vida em sociedade. Consideramos também a violência do ponto de vista histórico e cultural, como ação que envolve a percepção de agentes a respeito dos limites ou das perturbações de acordos tácitos, entendimentos e regras sociais que podem ser gerados por excessos no uso da força, causando efeitos negativos e prejuízos à coletividade (Zaluar, 2004).

O cenário escolhido para refletir sobre a relação entre violência e democracia é a periferia de Fortaleza (CE), onde realizamos há cerca de 10 anos pesquisas sobre crime, violência, segurança, justiça e cidadania. Os resultados apresentados aqui envolvem vasto material etnográfico recolhido em tempos e espaços diferentes, mas tendo como fio condutor a questão dos efeitos políticos e morais da violência urbana na vida de moradores de bairros populares, localizados na periferia de Fortaleza ${ }^{4}$. Nossas incursões pela capital cearense se concentraram em bairros da região do Grande Bom Jardim (Bom Jardim, Canidezinho, Siqueira, Granja Lisboa e Granja Portugal) e no Conjunto Ceará ${ }^{5}$. Apesar de serem locais com características muito diferentes, adotamos, para fins desta reflexão, a ideia de que os problemas são comuns à população em geral, embora em graus diferenciados. Essa generalização permite que nos concentremos no caráter compreensivo dos problemas relacionados à violência urbana nesses locais, explorando falas de moradores que ressaltam problemas comuns às comunidades da região. Em todos esses locais, os moradores tinham algo a dizer sobre a violência, sobre como ela afeta suas vidas, suas relações com o espaço público, as instituições e os governos responsáveis pelo controle social.

Trabalhamos no texto a compreensão dos efeitos políticos da violência urbana no cotidiano de moradores de bairros populares, explorando as suas percepções sobre seus relacionamentos com as pessoas que vivem naquele território, as instituições estatais responsáveis pelos direitos de cidadania e o papel dos governos na estruturação da ordem social vigente. Em nossas incursões etnográficas, realizamos conversações e entrevistas com moradores da periferia de Fortaleza, com intenção de ouvir deles como a violência afeta seu cotidiano. Utilizamos o diário de campo e, na medida do possível, contamos com dispositivos de gravação de áudio e filmagens para registro das falas dos moradores sobre as temáticas que nos interessavam. No presente texto, exploramos falas representativas de ideias fundamentais para pensar como os problemas cotidianos relacionados à violência afetam representações e práticas concernentes à organização de um Estado democrático de direito. No vasto material coletado, encontramos maneiras de olhar para a sociedade e falar dela como um lugar político e moral que envolve a participação dessas pessoas no debate sobre a cidade, a administração pública, o direito, a justiça, a cidadania, a segurança, entre outros problemas práticos vividos no dia a dia de uma sociedade democrática.

Para compreender a perspectiva que tentamos mobilizar aqui, submetemos nossas preocupações sociológicas às preocupações dos nossos interlocutores, em um exercício de compreensão e diálogo constante sobre como eles achavam que a violência urbana afeta suas vidas e suas expectativas e em relação ao que os poderes públicos deveriam fazer em razão disso. Em vez de chegar até nossos interlocutores com perguntas prontas, deixamos que eles falassem abertamente da violência, do Estado, da cidadania, sem nos preocuparmos em ter um conceito definido para cada tópico. Deixamos que a partir das falas deles os conceitos fossem surgindo e apresentaremos aqui nosso trabalho orientado pelas falas de interlocutores que não foram escolhidos, mas encontrados em diversos momentos de pesquisas, passagens, visitas e presenças que se construíram de maneira espontânea e conectadas umas pelas outras. Obviamente, nossas entradas variaram no campo, em conformidade com as demandas e experiências que julgamos importantes conhecer como espaços de associações, organizações não governamentais, instituições governamentais, escolas e residências de interlocutores que foram aparecendo durante o processo. Ao fim, apresentamos, então, não um produto absoluto, mas uma leitura orientada pelas nossas escolhas e encontros ao longo dos nossos processos de pesquisa na periferia de Fortaleza.

Do ponto de vista analítico, tentamos compreender a violência urbana como um fenômeno social que produz ecos na vida social de quem ocupa um lugar na cidade considerado marginal em virtude de sua posição geográfica e econômica. São alguns dos efeitos sociais para a democracia que abordaremos neste texto a partir do que os moradores nos falaram sobre o problema da

4 Entre as iniciativas de pesquisa que possibilitaram a escrita deste trabalho, destacamos os incentivos matérias e simbólicos decorrentes do projeto "Etnografias urbanas: redes, conflitos e lugares", apoiado pela Fundação Cearense de Apoio a Pesquisa (FUNCAP), com recursos do Programa de Apoio a Núcleos de Excelência (PRONEX).

5 Optamos para fins deste trabalho em não identificar nossos interlocutores e suas localizações em razão dos cuidados que envolvem a disposição de pessoas em falar da violência nos seus lugares de moradia (Paiva, 2014). 
violência urbana. Tomamos as falas dos nossos interlocutores como formas de interpretar, explicar e dar sentido à vida social, nas suas mais diversas formas de experimentação cultural e política, com fundamento em limites éticos e morais que, historicamente, envolvem o uso da força. Essas falas compõem um vasto acervo que agora nos ajuda a entender o que trabalharemos aqui como ecos da violência em uma sociedade democrática transpassada por situações limites que afetam o cotidiano e a cidadania. Tencionamos conhecer as rotinas e a visão do morador sobre a periferia e as marcas da violência nesses lugares. Deparamo-nos então com uma vastidão de experiências narradas sobre como a violência afeta a vida social e impõe aos moradores problemas práticos que são retratados como indignos de uma sociedade democrática, organizada em torno de um Estado que cobra impostos e deveres sem oferecer a devida retribuição para a garantia da segurança e do pleno exercício da cidadania. Interessou-nos saber como são orientadas as expectativas sociais em cotidianos marcados por situações de violência em uma sociedade democrática, explorando as contraposições entre o dever ser e a prática existente ali na margem.

Foi tentando resolver problemas empíricos que envolvem questões teóricas e políticas que encontramos em estudos sobre os limites das referências políticas e morais da vida social algumas possiblidades analíticas importantes para este trabalho (Feltran, 2010). As margens são aqueles lugares que, do ponto de vista analítico e crítico, podemos compreender a partir dos limites e das fronteiras existentes para normalização da vida social. São os lugares em que as ordens vigentes encontram suas denominações limítrofes, criando modulações para impedir seu próprio transbordamento. Das e Poole (2008) articularam uma reflexão sobre as margens baseada em uma estratégia analítica e descritiva de afastamento da imagem consolidada do Estado como forma administrativa de organização política racionalizada. Isso lhes permitiu compreender problemas como o da prerrogativa do monopólio da violência legítima desde as nuances da relação entre a violência e as forças ordenadoras do Estado na vida das pessoas em uma comunidade política e moral. E permite ainda, entre outras coisas, explorar séries de possibilidades analíticas de realidades sociais em movimento de acomodação e resistência em relação a ordens vigentes de um mundo compartilhado entre pessoas reconhecidas, em uma democracia, como portadoras de direitos. As fronteiras entre legalidade e ilegalidade, legítimo e ilegítimo, formal e informal são pressupostos das margens, em que o Estado não consegue impor sua sanção normalizadora, atuando ele próprio fora dos regimes constituídos pela força do direito e da lei (Agamben, 2004). Olhar a democracia desde as suas margens é uma maneira de olhar para o mundo social de um lugar não formal, muito menos confortável, em virtude da abertura para os mais variados problemas políticos, morais, teóricos e práticos de uma investigação sociológica.
A apresentação dos resultados terá a seguinte configuração: 1) incialmente, exploramos conceitualmente os problemas da violência urbana para a democracia, situando algumas questões analíticas de estudos de cientistas sociais que se debruçaram sobre o tema;2) depois, adensamos a conceituação de ecos da violência à luz das falas de moradores da periferia de Fortaleza sobre essa temática, explorando problemas sociais apontados por eles como consequência de eventos violentos no seu cotidiano; 3) por fim, observamos a construção social de diferenciações e separações que tecem uma forma peculiar de vivência democrática e experimentação de uma cidadania entre pessoas que se reconhecem e são conhecidas como cidadãos ou bandidos, dignos de portar direitos ou não, gozar da proteção do Estado ou não.

\section{A violência urbana como problema social de uma sociedade democrática}

O primeiro esforço analítico deste trabalho perpassa a compreensão de como a violência urbana afeta as dinâmicas constitutivas de uma sociedade democrática de direito. Conforme observou Santos (1999), desde a década de 1970, com o advento da "sociedade global", emergem outras formas de sociabilidade e conflitualidade nas cidades ocidentais, principalmente nas latino-americanas, com enfoque em uma nova morfologia de problemas sociais. Uma das características dessa nova configuração de problemas sociais é o aumento de processos estruturais de exclusão social, fundamentados na desigualdade de renda, nos quais um dos efeitos é a expansão das práticas violentas, seja na resolução dos conflitos ou como estratégia de aquisição de bens materiais. É oportuno ressaltar que, na América Latina, os processos de formação dos estados nacionais envolveram desde a violência da colonização, passando pela escravatura até os golpes militares que implementaram estados de exceção em praticamente todos os países do continente. Briceño-León (2002, p. 35) chama-nos a atenção para isso:

La violencia no ha sido ajena a los procesos de cotidianidad o transformación social de América Latina: violenta fue la conquista, violento el esclavismo, violenta la independencia, violentos los procesos de apropiación de las tierras y de expropiación de los excedentes. Pero en la actualidad hablamos de un proceso distinto, singular, y que se refiere a la violencia delincuencial y urbana.

O autor observa que os processos de democratização são acompanhados da intensificação de práticas criminosas retratadas, por exemplo, em taxas de homicídio entre as populações urbanas. No Brasil, Adorno (2002) evidencia que a ascensão da democracia é 
acompanhada pela emergência da violência urbana como problema social significativo para as populações e os governos estaduais responsabilizados constitucionalmente pela segurança pública. Segundo Barreira (2004), a democratização brasileira imprimou novos desafios para constituição da lei e da ordem, em virtude tanto da difusão da violência quanto das crises internas dos órgãos responsáveis pela segurança pública e pela defesa dos direitos de cidadania. Essa nova configuração de problemas sociais envolveu processos de legitimação das instituições que integram as pessoas às instituições de poder características de um regime democrático. Apesar da violência nas cidades brasileiras atingir todas as classes sociais, ficou evidente, na década de 1990, as diferenças entre ricos, médios e pobres em razão, justamente, das possibilidades de manejo desses estratos às condições oferecidas pela nova ordem institucional do regime democrático de direito implantado no país.

Nas décadas de 1990 e 2000, a criminalidade violenta ganhou visibilidade e passou a ser tratada pelas diversas instâncias governamentais como problema significativo das grandes cidades brasileiras (Zaluar, 2004). Nesse período, o tráfico de drogas e armas sedimentou controles em territórios urbanos e contingentes populacionais que passaram a viver sob o domínio de pessoas "fora da lei". Essa situação criou inúmeras dificuldades para quem vive, sobretudo, nas comunidades mais pobres do país, onde o tráfico encontrou as condições ecológicas adequadas para sua proliferação (Beato F., 1998). Nesse contexto, como evidenciou Zaluar (1985), os pobres urbanos se encontram em uma situação de dupla exclusão, pois são as principais vítimas e os principais acusados de crimes nas cidades, experimentando situações de discriminação em função da sua posição desprivilegiada frente aos segmentos mais bem posicionados política e economicamente.

É importante destacar a ideia de que, no contexto das grandes cidades brasileiras, algumas periferias se tornaram símbolos da violência em determinadas cidades. As favelas, por exemplo, carregam em si uma pesada carga depreciativa, juntamente com bairros populares que experimentam taxas de criminalidade significativas, com ampla visibilidade na mídia e atenção especial dos governos em suas ações de enfrentamento à violência urbana. Por meio de uma superexposição da violência nas áreas desprestigiadas da cidade, criou-se uma espécie de doxa sobre os bairros populares, pautada na homogeneização das suas diferenças, sem nenhuma relativização das distinções concernentes à sua população (Paiva, 2014). A marginalização das áreas mais pobres e dos seus moradores criou dificuldades efetivas para consolidação e efetivação dos direitos civis de segmentos consideráveis da população brasileira. Para Caldeira (2003), no Brasil, a consolidação da democracia e dos direitos políticos ocorreu sem a efetivação de direitos civis e sociais. Deste modo, os segmentos populares foram integrados ao jogo político, mesmo que apenas pelo direito ao voto. Não obstante, eles não experimentaram melhorias significativas nas suas condições de vida, continuando a sofrer com problemas como a desigualdade social, a falta de acesso a serviços públicos essenciais e as graves violações dos seus direitos individuais promovidos pelo próprio Estado, como nos casos de abusos das forças policiais promovidos nas áreas mais pobres das cidades (Silva e Leite, 2007).

Velho (1996, p. 14) insistiu nessa ideia, argumentando que para se compreender o tema da violência, na sociedade brasileira, é preciso saber que a população "experimenta uma situação em que a cidadania não se impôs como valor nem implementou mecanismos democráticos que possibilitassem o desenvolvimento de um sistema sociopolítico minimamente satisfatório para a maior parte da população do país". Esses processos reverberam na vida social dos brasileiros e na dinâmica das suas instituições de segurança e justiça. Misse (2008) afirma que, enquanto para o Ocidente moderno a socialização da acusação social foi um dispositivo importante para operacionalização de um sistema jurídico capaz de ordenar o monopólio da violência legítima, no Brasil, a delação prevaleceu como recurso que sobrecarregou as forças policiais e as instituições responsáveis pela segurança e pelo controle social. Entre as consequências disso, está a violência policial que, como explicam Machado e Noronha (2002, p. 218), não se trata apenas de um fenômeno de cima para baixo, mas "é parte de um sistema que, abrangendo autoridades e cidadãos, coloca o combate da criminalidade acima da aplicação da lei e proteção da sociedade". Essas dinâmicas têm afetado a vida dos moradores da periferia de maneira abrangente, colocando as populações locais no entremeio da violência perpetrada por criminosos e acentuada pelas forças policiais em nome da lei e da ordem. Ao situar a discussão, muito estreita e rapidamente, partimos agora para explorar o que desejamos tratar como ecos da violência na vida de pessoas comuns, residentes na periferia de Fortaleza.

\section{Ecos da violência na periferia de Fortaleza}

Para compreender as dinâmicas da violência e como ela repercute na vida social, caracterizando formas muito particulares de vivência democrática por meio da experiência social de sujeitos de direito, recorremos à ideia de que manifestações da violência ecoam nas falas de moradores sobre o seu cotidiano. $\mathrm{O}$ eco como conhecemos é a repetição de um som produzido pelo reflexo das ondas sonoras, tendo como seu sentido figurativo a repetição das palavras ou ideias de outra, ou outras pessoas. Nesta perspectiva, um eco pode ser aquilo que é repetido muitas vezes em razão do acolhimento que as pessoas deram àquela ideia e, portanto, 
reverberam em diversas direções. $\mathrm{O}$ eco produz o rumor $^{6}$, ou seja, as falas que propagam a situação, agregando à sua propagação novos significados que irão resultar em múltiplas apropriações do que o evento poderá vir a significar. Os ecos da violência correspondem aos efeitos simbólicos e políticos de experiências morais que, em certa medida, marcam os limites referentes ao que as pessoas acreditam ser razoável em virtude das expectativas sociais estruturadas por relações e possibilidades de usos da força entre os que compõem uma comunidade política.

Em linhas gerais, os ecos da violência são formas de estruturar relações sociais e constituem maneiras de sujeitos falarem e se comportarem diante de situações de violência conhecidas e repetidas por pessoas que compartilham experiências de aproximação do fenômeno (Freitas, 2003). Entre os ecos mais significativos estão situações de medo e distinção social entre aqueles que são protagonistas e vítimas de manifestações da violência.Assim, os ecos da violência criam efeitos simbólicos e políticos importantes para quem vive na periferia de Fortaleza. Essas pessoas presenciam e repercutem histórias que se repetem, criando circuitos relacionais entre os que vivenciam práticas comuns e enunciações de experiências e ideias compartilhadas e constitutivas de um lugar "marcado pela violência". Entre as consequências desse processo, está o enfraquecimento das possibilidades de vivência cotidiana baseadas no compartilhamento de direitos e deveres comuns, com a emergência de ações orientadas pela crença na ineficiência do Estado em sua função de manter o monopólio da violência legítima e garantir o respeito aos direitos de cidadania.

"Aqui ninguém anda à noite porque é assalto na certa", afirmaram os moradores das áreas pesquisadas. Andamos pelas ruas dos bairros investigados e, em vários momentos, encontramos pessoas que nos narraram muitas histórias incríveis de assaltos, latrocínios e lesões corporais ocorridas nesses locais. São histórias de pessoas conhecidas ou não cuja experiência de ser vítima de violência passou a compor as falas e os imaginários de quem evita sair pelas ruas dos bairros à noite. Não apenas histórias de assaltos são importantes, como histórias de assaltantes, menores ou adultos, velhos conhecidos na comunidade que ajudaram a construir as limitações para o trânsito livre de pessoas. Nos bairros visitados, também é comum a menção a assaltantes de outros bairros, pessoas que vêm até ali apenas para assaltar e depois voltam para seus lugares de origem. Essas situações compõem repertórios de enunciação que passaram a ordenar as vidas em razão das possibilidades de a pessoa ser vítima de um assalto.
Obviamente os assaltos não são apenas histórias inventadas, mas seus efeitos estão muito além da manifestação empírica desse tipo de crime nas comunidades. A mudança de atitude de moradores frente aos assaltos não segue a mera observação de uma situação negativa, ela é construída em torno da ideia de que as ruas são perigosas e por isso devem ser evitadas, pois ali alguém foi assaltado ou morreu mesmo sem reagir a um assalto. A situação narrada não é simplesmente baseada em uma mentira, mas seu alcance corresponde ao eco produzido pela situação de violência que se espalha e alcança muitos outros moradores, produzindo a repetição de ações correspondentes à necessidade de se evitar assaltos.

O medo é um dos principais ecos da violência, e seu alcance não necessariamente envolve uma experiência empírica vivida pela pessoa autora da fala (Freitas, 2003). Ouvimos dos moradores apreensões sobre o que significa para eles, por exemplo, andar à noite ou sozinhos pelas ruas de seus bairros. Tal atividade parece assustadora, pois envolve o perigo eminente de ser surpreendido pelos assaltantes às espreitas. Inclusive, parece haver sempre alguém à espreita pelo modo como as pessoas andam atentas, olhando, medindo, calculando possibilidades. "Eu saio correndo do trabalho pra pegar o ônibus de 18h30. O que passa meia hora depois vem vago, enquanto esse vem lotado. Eu prefiro assim porque é mais difícil dos assaltantes agirem", explica um morador que trabalha no centro da cidade. Para evitar surpresas, é comum, também, carregar um celular menos valioso, o "do ladrão", ou fotocópias de documentos no lugar dos originais. Essas são atitudes que as pessoas adotaram em razão do que ouviram e dizem que existe nos seus bairros. Circular por ele é um perigo, carregar objetos de valor e quantias de valor, "uma loucura". É preciso governar os desejos, reprimir vontades, controlar necessidades para se acomodar à dinâmica de uma vida medida pela possibilidade de evitar assaltos.

Nem sempre ficar em casa é seguro. É importante observarmos que as casas se tornaram pequenas fortificações ${ }^{7}$, repletas de grades, cercas elétricas, câmeras de segurança e adesivos de empresas de vigilância. "Os bandidos hoje não têm mais limites, eles invadem, roubam a gente e se puder ainda esculacham". Esse medo é comum e sentido na entrada e saída das residências. Passamos por situações em que abordar o morador em sua entrada ou saída de casa nos trouxe o constrangimento de ter que explicar a pesquisa que estávamos fazendo para alguém que visivelmente se assustou e ficou apreensiva com nossa abordagem. "Rapaz até me assustei porque aqui a gente nunca sabe quem é quem", disse-nos um jovem de 17 anos ao nos encontrar na

6 Para Das (2008), o rumor ocupa uma região da linguagem que nos permite experimentar acontecimentos e interpretações que o ampliam pelos próprios atos de enunciação. Ver também Das (2006).

7 Caldeira (2003, p. 211) explica que os enclaves fortificados são "espaços privatizados, fechados e monitorados para residência, consumo, lazer e trabalho". Esses espaços têm um ordenamento nas classes médias e altas, sendo que nas camadas populares observamos que as fortificações seguem projetos mais espontâneos relacionados ao processo de autoconstrução dos domicílios pelos seus moradores. 
entrada da sua casa.Viver com medo não é uma opção, mas uma condição com a qual as pessoas se acostumaram e passaram a organizar suas rotinas, sendo possível falar que o medo gera circuitos muito particulares em virtude das aproximações e distanciamentos criados por esse sentimento. Esta situação nos remete a outro momento da fala do jovem morador abordado em que ele retoma um ditado popular que diz o seguinte: "viver com medo é viver pela metade". Ressaltava essa ideia para ilustrar os problemas de uma sociedade democrática em que a cidadania não é vivida plenamente, entre outras coisas, devido ao medo permanente de ser vítima de um crime.

Situações de invasão à residência são experiências recorrentes, impactando em mudanças estéticas e culturais nos bairros mais pobres. Muros altos e com pouco espaço para ventilação tornam os ambientes domésticos bastante escuros e quentes. "Rapaz, a gente tinha uma casa ventilada, mas agora eu subi o muro e coloquei telhado aqui para não ter brecha pra bandido", relata um taxista local que modificou a casa em prol da "segurança da família”. Mudanças como a do nosso interlocutor são comuns e revelam tentativas de diminuir os perigos de uma situação que acontece na vizinhança e gera ecos nas vidas de pessoas que têm sua residência fortificada. Enquanto as elites criaram espaços segregados para se separar das populações que residem nas periferias, os mais pobres agregaram as fortificações aos seus projetos de autoconstrução. $\mathrm{O}$ que observamos, na periferia de Fortaleza, é a prevalência da iniciativa do morador como solução individualizada para problemas que afetam a esfera pública dos bairros estudados. As fortificações também desqualificam, esteticamente, os bairros da periferia ao tornar a paisagem árida e pouco propícia à sociabilidade, em virtude do medo de cada um ser a próxima vítima da violência.

As fortificações das residências também são comuns em estabelecimentos comerciais. Grades separam o cliente do comerciante. Em determinadas horas, os comerciantes relatam que o melhor é fechar as portas. Foi comum observar comércios fechados de $12 \mathrm{~h} 00$ às 14 h00 e depois das 21h00. São horários em que as práticas de assalto, segundo nossos interlocutores, são comuns. Apesar de evitar esses horários, os crimes continuam acontecendo, e as grades não parecem evitar que os estabelecimentos sejam assaltados, mas "pelo menos a gente cria uma dificuldade para o meliante", explica um comerciante. Abrir um comércio também precisa ser avaliado segundo o sentimento de medo dos assaltos. "Rapaz hoje aqui o cabra tem que ter coragem para abrir um negócio porque a bandidagem tá solta pelo mundo", explicou um ex-dono de uma lan house. Assim, o medo afeta a economia local e as possibilidades de livre iniciativa e interação entre pessoas que utilizam sua percepção da violência para calcular boa parte das suas ações nos seus locais de moradia.
É necessário explicar que, como demonstraram estudos realizados nos Estados Unidos, o medo do crime afeta muito mais as pessoas do que o crime em si (Warr, 2000). Embora considere o medo como um sentimento importante, que inclusive funciona como salva-vidas em muitas ocasiões, Warr ressalta que, sob as circunstâncias erradas, ele pode restringir o comportamento social devido a informações incertas sobre os riscos do crime. O problema brasileiro, como destaca Paulo Sérgio Pinheiro, no prefácio do livro do sociólogo estadunidense Barry Glassner (2003), é o fato de o país experimentar taxas significativas de crimes violentos nas suas principais cidades, sobretudo, nas suas periferias. Isto não significa dizer que não existam contradições entre o que as pessoas sentem e o que de fato são as circunstâncias objetivas de vitimização. Há pessoas, nos locais investigados, que perderam qualquer vínculo com as ruas, praças e outros locais públicos do seu bairro. Pouco importa para elas o quanto um lugar seja "realmente" perigoso, pois vivem rotinas repletas de restrições impostas pela expectativa de ser uma vítima de crime a qualquer hora do dia, em qualquer lugar do bairro onde moram. O medo, neste sentido, pode ser relacionado a atitudes antecipatórias a situações presumivelmente violentas, relegando as pessoas à reclusão e ao enclausuramento (Freitas, 2013).

Nos seus estudos sobre o medo do crime em bairros estadunidenses que passam por processo de declínio urbano, Skogan (1986) demonstrou que esse fenômeno pode levar os indivíduos a se retirarem física e psicologicamente das sociabilidades do lugar, aumentando assim as possibilidades de decadência de um determinado território urbano. Essa observação é bastante pertinente, sobretudo, em nossas observações dos espaços públicos dos bairros analisados. Talvez, o exemplo mais interessante das nossas pesquisas seja o caso do Polo de Lazer Luiz Gonzaga, no Conjunto Ceará. Construído na década de 1990, na gestão do então prefeito Ciro Gomes, o local era uma espécie de praça com diversas atrações para o lazer da população, com campo de futebol, área de skate, bares, restaurantes, igreja, associação de moradores, centro cultural e espaço privilegiado de grandes eventos, como as festas que marcam a história do bairro ${ }^{8}$.

Estivemos no Polo de Lazer Luiz Gonzaga em 2014 e identificamos algumas situações interessantes. Entre elas, a baixa circulação de pessoas em um espaço que, segundo seus moradores, era o mais frequentado do bairro. Para estimar essa situação, observamos que a duas ruas do polo uma pequena multidão utilizava uma avenida do Conjunto Ceará para fazer cooper. Ao perguntar a um morador que nos acompanhava, nas andanças pelo bairro, porque essas pessoas não utilizavam o polo em vez daquela rua para a prática do exercício físico, ele foi enfático: "as pessoas têm medo 
dos assaltos”. A degradação do lugar, o estado de abandono e a pouca iluminação permitiram que usuários de droga ocupassem certos pontos e práticas de assalto, eventualmente, ocorressem no local. Não obstante, para os moradores que continuavam a frequentar o lugar, o polo era relativamente tranquilo, embora precisasse de reformas, inclusive devido à ocupação irregular e o matagal que passou a compor a realidade desse espaço de lazer da comunidade. Para as pessoas que encontramos no polo, o medo é infundado, e a saída de muitos frequentadores é o que realmente vai dando a ele um ar de lugar degradado e abandonado. Estratégias para atrair pessoas são recorrentemente acionadas por movimentos sociais que enxergam o espaço como um dos mais importantes para a sociabilidade local, integrando a comunidade em um ambiente comum de encontro e interlocução.

Em nossas investigações e conversas com policiais que atuam no Conjunto Ceará, a situação do polo não é diferente da de outros locais como a rua em que as pessoas praticavam cooper. $\mathrm{O}$ ar de degradação, no entanto, contribuiu para que os moradores não estejam no polo. Mesmo com um distrito policial funcionando no polo de lazer, a sensação de insegurança afasta possíveis frequentadores, sobretudo, em pontos de pior iluminação pública e sem concentração de qualquer estabelecimento comercial. Jovens que consomem drogas em áreas do polo são acusados, sistematicamente, de serem autores de assaltos no local, mesmo que não existam provas objetivas contra eles. $\mathrm{O}$ rumor, entretanto, cumpre um papel decisivo em registrar e deixar muito evidente a existência de prováveis autores de assaltos e, portanto, sujeitos que devem ser evitados na medida do possível. Este é outro eco forte da violência que, no Brasil, cumpre um papel importante na maneira como os direitos democráticos constitutivos da nossa democracia são separados entre quem é cidadão e quem não goza da mesma consideração. A essa separação entre quem é e não é cidadão dedicamos algumas reflexões que julgamos fundamentais para entender como os ecos da violência afetam a vida das pessoas em uma sociedade democrática de direito.

\section{Repartição do mundo: entre o bem e o mal}

Os moradores da periferia de Fortaleza reproduzem nas suas relações algo que não é uma singularidade deles e pode ser observado em outros contextos sociais, como revelam estudos que analisam as separações e diferenças sociais entre pessoas de bem e os considerados como marginais (Misse, 2010). Essa configuração pode assumir várias formas, como aquelas entre trabalhador e vagabundo, honesto e malandro, cidadão e bandido, entre outras formulações que se relacionam a peculiaridades locais. Apesar das diferenças, as classificações funcionam como dispositivos modulares em que o sujeito é enquadrado conforme os valores constitutivos do que as pessoas julgam ser bom ou ruim, certo ou errado, honesto ou desonesto, legal ou ilegal. Essas conceituações escapam do primado da lei para assumir as formas de verdade construídas em torno das moralidades típicas das correlações de força e sociabilidades estruturantes das relações de vizinhança operadas em determinada conjuntura local. Em geral, são classificações que buscam retratar sistemas de pensamento que visam ressaltar o papel do bem e do mal nas comunidades estudadas. Ao observarmos como nossos interlocutores operavam e nos explicavam as diferenças entre pessoas boas e más, recordamos a clássica reflexão de Nietzsche (2000, p. 72-73) a respeito dos costumes e da moral.

Ser moral, morigerado, ético significa prestar obediência a uma lei ou tradição há muito estabelecida. Se alguém se sujeita a ela com dificuldade ou com prazer é indiferente, bastando que o faça. "Bom" é chamado aquele que, após longa hereditariedade e quase por natureza, pratica facilmente e de bom grado o que é moral, conforme seja (por exemplo, exerce a vingança quando exercê-la faz parte do bom costume, como entre os antigos gregos). Ele é denominado bom porque é bom "para algo"; mas como, na mudança dos costumes, a benevolência, a compaixão e similares foram sentidos como "bons para algo", como úteis, agora sobretudo o benevolente, o prestativo, é chamado "bom". Mau é ser "não moral" (imoral), praticar mau costume, ofender a tradição, seja ela racional ou estúpida; especialmente prejudicar o próximo foi visto nas leis morais das diferentes épocas como nocivo, de modo que hoje a palavra "mau" nos faz pensar sobretudo no dano voluntário ao próximo.

Conforme ressalta Nietzsche, a experiência de ser bom ou mau envolve as tradições que constituem os costumes estabelecidos, compreendendo as ações que os sujeitos empregam na sua relação com os outros. Em linhas gerais, a reflexão a respeito da moral empreendida por Nietzsche nos ajuda a entender um pouco mais as diferenças sociais que são estruturantes da democracia brasileira, pois o exercício da cidadania nas periferias urbanas do país passa, necessariamente, por distinções que implicam diretamente nas formas de acesso e reconhecimento dos direitos de cidadania. Para Holston (2013), enquanto as democracias se fundamentam na promessa de cidadanias mais igualitárias, suas pesquisas, na periferia de São Paulo, nos anos 1980, revelaram usos da palavra "cidadão" como meio de moradores se diferenciarem e estabelecerem distâncias. Segundo ele, ao conversar com moradores de São Paulo, percebeu que "cidadania é uma medida de diferença e uma forma de distanciar as pessoas umas das outras" (Holston, 2013, p. 23). Nos seus estudos, na década de 2000, ele 
demonstra a irrupção de uma cidadania insurgente nesses espaços de diferenciação, no entanto, para nossa análise, preservaremos esse caráter distintivo da cidadania diferenciada porque ele parece extremamente atual para o caso de Fortaleza.

Ao seguir a reflexão de Nietzsche sobre o "homem bom" e o "homem mau", observamos que essa separação moral é extremamente importante para os moradores da periferia ao falarem de si e dos outros. As narrativas dos moradores nos revelaram que, em certa medida, o cidadão é este ser bom, cuja vida, mesmo cheia de percalços, não o desvia do caminho moral e do comportamento ético presente nas representações socialmente constituídas e historicamente incorporadas pela experiência e percepção dos moradores. $\mathrm{O}$ cidadão, homem e mulher de bem, é o trabalhador que, mesmo com "muito sacrificio", nunca se deixa levar pela possibilidade de obter "dinheiro fácil", ganho de modo desonesto. A honestidade e o sacrifício são características fundamentais do cidadão, ressaltadas para explicar a estima e a nobreza do seu comportamento moral impecável. Ele trabalha duro e sustenta sua família com o suor do seu corpo, sem se desviar do caminho do bem em prol de formas mais fáceis de conseguir seu sustento ou mesmo um alívio na sua rotina. $\mathrm{O}$ cidadão tem seu direito assegurado não porque vive em uma sociedade democrática de direito. Ele o tem como uma conquista moral decorrente do que faz em prol do reconhecimento da sua cidadania.

Em contrapartida ao cidadão, há "a pessoa que não presta", o "cabra safado", "ordinário", "piranqueiro", "cretino", "mau elemento", "meliante", "drogado", "vagabundo" e "bandido". São "meliantes", "elementos que não prestam”, aqueles cujo direito não é reconhecido a não ser "pelos taus dos direitos humanos que querem defender bandido" . O bandido, sujeito desonesto, não quer trabalhar, por isso investe sua energia em roubos, furtos, tráfico de drogas e armas e causa o terror na comunidade. Na periferia, ele não respeita ninguém e, segundo nossos interlocutores, é responsável por todo tipo de maldade. Suas ações desrespeitam os direitos das pessoas, pois sua índole não reconhece no outro um sujeito que tem seus direitos resguardados. Por isso, não é possível que alguns de nossos interlocutores entendam como é possível reivindicar "direitos para o bandido". Ele não deve ter acesso ao direito porque, na concepção dos nossos interlocutores, está fora da ordem e, portanto, das instâncias que regulam o sistema de justiça de uma ordem democrática. Como evidencia Misse (2010, p. 23), “o rótulo de 'bandido' é de tal modo reificado no indivíduo que restam poucos espaços para negociar, manipular ou abandonar a identidade pública estigmatizada".
Ao falarem do cidadão e do bandido, nas entrevistas, os moradores não parecem trabalhar com afirmações que traduzem conceitos definidos objetivamente, explorando, grosso modo, imagens e rumores sobre pessoas que eles não conhecem minimamente. $\mathrm{O}$ jeito de vestir, andar pela rua, perambular pela vizinhança, consumir drogas, beber em horários em que deveria estar trabalhando, entre outras ações moralmente questionáveis, colocam a pessoa na lista dos que possivelmente têm algum envolvimento com o crime. Andar pela comunidade com um "mau elemento" pode ser o suficiente para que seja atribuída à pessoa a alcunha de bandido, e assim, se fala dela como sujeito de comportamento questionável cuja cidadania lhe é negada. Isso pode aparecer fortemente delimitado tanto na vida quanto na morte dessa pessoa. É muito comum, por exemplo, que em caso de a pessoa ser vítima de assassinato, a suspeita de ter um envolvimento com o crime desprestigie a sua morte, oferecendo-lhe uma explicação que, em geral, pode impactar na baixa expectativa de resolução daquele acontecimento. "Ah, ele é bandido", é uma expressão usual para explicar a morte de pessoas, tornando-a razoável por ser isso que acontece aos bandidos. Para entrevistados, "eles matam e eles morrem". Nossos interlocutores pareceram concordar com a ideia de que, nesses casos, não há o que fazer, pois os mortos cumpriram o que a vida lhes reservou e o poder público tem casos mais importantes para dar conta. Quando morre uma pessoa considerada cidadã, é possível ver um tratamento diferente, inclusive com manifestações de revolta da população, o que não acontece quando bandidos ou suspeitos morrem.

Encontramos nas nossas conversas e entrevistas pessoas que narraram casos em que o crime foi protagonizado por um "cidadão". Percebemos que, em certos casos, a participação em um crime não destrói por completo a imagem de alguém visto como um cidadão pela comunidade. Em um acontecimento que acompanhamos, o marido assassinou a mulher que, para os vizinhos, era uma "vagabunda". "Ela vivia se agarrando com outros, prestava não", explicou uma vizinha do casal. Assim, ao ver ela com outro homem na rua, o marido lhe aguardou em casa, desferindo três mortais golpes de faca. Mesmo depois de assassinar a mulher, as pessoas falavam que ele era um trabalhador, um cidadão. Vivia da casa para o trabalho e para dar de tudo à mulher e aos dois filhos que passaram a ser criados pela avó em virtude da "tragédia que se abateu na família". Uma infelicidade, pois ali era um "cidadão que ia preso" por não ter contido a raiva diante da traição de uma "mulher bandida". Nesse caso como em outros acontecimentos, constatamos que embora os crimes de honra tenham saído dos nossos códigos legais, continuam

9 É comum ouvir pessoas se referirem aos "direitos humanos" como algo que privilegia bandidos. Sobre isso, Caldeira (2003) chamou a atenção para o surgimento de uma visão negativa dos direitos humanos no Brasil, ressaltando o enfoque dos movimentos identificados pela sua luta em torno da questão carcerária. 
plenamente atuais no imaginário das pessoas que veem, escutam e falam dos crimes que conhecem.

Analisamos também que há poucas possibilidades para um bandido mudar seu status quo na comunidade. O caráter depreciativo da sua imagem na periferia de Fortaleza, em geral, sofre alguma mudança quando ele consegue convencer os moradores de uma transformação substantiva na sua conduta, o que necessita de provas muito contundentes para afetar seu reconhecimento na comunidade. "Ele era um bandido dos mais perversos aqui do bairro, mas encontrou Jesus e hoje é uma pessoa do bem, que ajuda muito todo mundo aqui na comunidade", fala um morador a respeito de seu vizinho, um senhor de 68 anos casado, com três filhos e dono de um negócio que gerencia com sua mulher. Falamos com esse senhor que, em uma entrevista cuidadosamente negociada, nos revelou que chegou a matar uma pessoa e passou dez anos preso, "pagando pelo crime". "Hoje, graças a Deus, eu encontrei Jesus e a minha vida é outra", conta-nos afirmando que muita gente sabe do seu passado, mas reconhecem a mudança efetiva que ele experimentou. Isso não aconteceu sem resistência ou sem medo e desconfiança, mas atualmente ele vive uma vida reconhecida pela comunidade como uma "vida de uma pessoa de bem", ou seja, um cidadão, decente e cumpridor da palavra de Deus. A entrada em uma igreja evangélica, segundo nosso interlocutor, foi fundamental para que as pessoas acreditassem na sua transformação.

As igrejas nos pareceram detentoras de um poder muito significativo, não apenas em termos de conversão das pessoas como também em função de garantirem uma mudança efetiva no seu status social. Nenhuma instituição consagrada pelo Estado democrático de direito brasileiro tem poder semelhante. As igrejas compõem um importante elo entre as pessoas na periferia e parecem realizar um trabalho importante para quem deseja ter seus direitos de cidadania restituídos. Cumprir a pena na cadeia e sair "recuperado" não é suficiente para que a imagem de um bandido mude na comunidade onde vive. Egressos do sistema prisional, em geral, são bandidos, conforme observamos nas falas analisadas. Nos bairros pesquisados, a única possibilidade de um bandido se tornar cidadão é por meio da sua conversão, sobretudo, em uma igreja evangélica cuja dinâmica do rito de passagem institucional envolve "aceitar Jesus na sua vida". Nenhuma instituição democrática de direito, conhecida na periferia de Fortaleza, exerce poder igual e permite o deslocamento do sujeito entre essas duas classificações estruturantes do modo de ver, sentir e falar do mundo em que vivem nossos interlocutores. As interfaces entre a religião e a vida social são conhecidas pelos sociólogos desde os trabalhos seminais de Max Weber e atuam, no contexto da periferia, como formas imbricadas de conceber as disposições morais de uma pessoa ${ }^{10}$.

Em suma, o que observamos nas maneiras de falar da violência e da cidadania são elaborações morais estruturadas não por uma concepção democrática de vida social, mas pelo fato de os direitos serem diferenciados e, portanto, restritos e limitados. As fronteiras morais criadas e reproduzidas pelas imagens de cidadão e bandido repercutem na vida social de quem vive e experimenta a democracia nas margens do Estado de direito. As experiências nessas margens são mobilizadas por diferenciações que tornam proibitivas circulações e aproximações entre pessoas que, em tese, vivem em um mesmo território da cidade e compartilham de problemas e condições sociais de existência. Não nos pareceu que a ideia de "todos" terem direitos iguais seja aceitável, pois para nossos interlocutores existem pessoas boas e pessoas ruins, e isso é importante para o reconhecimento da condição de cidadão. As primeiras podem errar ou as segundas podem mudar, contudo, isso é um processo que envolve os destinos de cada um na sua trajetória de vida. "Encontrar Jesus" pode ser algo que leva uma pessoa ruim ao bom caminho, assim como um passo em falso ou ceder a uma tentação pode levar uma pessoa boa ao mau caminho. São possibilidades existentes, e para nossos interlocutores, o papel dos governantes é manter a supremacia das pessoas do bem, ainda que para isso eles possam se exceder no seu papel e cometer ilegalidades ou crimes.

"Geralmente a comunidade nos chama pra 'resolver' a situação. Eles preferem que a gente dê umas porradas no vagabundo do que leve ele pra cadeia”, explica um policial com 12 anos de trabalho em bairros da periferia de Fortaleza. É muito comum que os moradores interpretem a ida à delegacia como uma perda de tempo, afinal, "a polícia prende, e a justiça solta" é um ditado extremamente repetido pelos nossos interlocutores. Isso retrata uma questão empírica referente ao fato de policiais realizarem prisões nas comunidades sem a manutenção da privação de liberdade por um tempo considerado como "justo" pelos moradores. Em algumas situações explicitadas por nossos interlocutores, "o policial leva o cara preso hoje, amanhã ele tá assaltando na comunidade". Policiais entrevistados nos explicaram que isso ocorre em função dos moradores se recusarem a oferecer denúncias e testemunhos, tornando impossível para os operadores de segurança pública a manutenção de certas pessoas presas. A falta de "colaboração da comunidade" dificulta, na visão deles, a precisão dos procedimentos legais, e isso possibilita que alguém continue livre mesmo quando "todos sabem que se trata de um bandido". Essa dificuldade gera o sentimento de ser mais prático que policiais "resolvam ali mesmo

10 Weber (2004) observou que a ascese religiosa presente na dinâmica de uma ética protestante foi fundamental para a criação de atitudes econômicas diferenciadas e geradoras de possibilidades fundamentais para o desenvolvimento do capitalismo moderno. 
a situação", aplicando aos detidos um sofrimento fisico equivalente à prática desviante que protagonizam. Chamou-nos a atenção o fato de os moradores sentirem o Judiciário como uma instituição distante, até irrelevante para suas vidas em virtude das dificuldades que o mesmo cria para resolução dos crimes na comunidade. "Não dá pra entender, os policiais prenderam ontem esses meninos e o juiz da infância no outro dia manda eles de volta", nos explicou uma liderança comunitária, ressaltando que, no bairro, os moradores só podem contar com "a justiça de Deus"11.

A separação entre cidadãos e bandidos reflete outro eco da violência observado na pesquisa. Ela retrata a perda de confiança tanto entre as pessoas quanto nas instituições que deveriam, em tese, cuidar das aproximações e dos distanciamentos entre quem vive em conformidade com as regras de convivência democrática e os que não as respeitam. Se considerarmos que a confiança no outro, em que ele cumpra certos preceitos legais e morais, é um elemento importante para ações sociais mutuamente referenciadas e compartilhadas intersubjetivamente para compor relações democráticas de confiança, podemos avaliar que a situação na periferia de Fortaleza é comprometida pelos ecos da violência nos processos de classificação social dos sujeitos que compõem uma comunidade política e moral. É muito importante ressaltar que, como observou Bauman (2003), uma comunidade se caracteriza pelo entendimento e compartilhamento de acordos tácitos entre os sujeitos que dela fazem parte. Ora, isso só pode vir a ocorrer de fato no desdobramento de relações de confiança baseadas no conhecimento e no reconhecimento de determinados acordos entre pessoas que partilham de um mesmo esquema referencial de entendimento ${ }^{12}$.

Ao refletir sobre as relações de confiança, Giddens (1991, p.38) observou que a confiança é distinta de sentimentos como a crença porque pressupõe consciência das circunstâncias de risco, embora ambos os conceitos, segundo o autor,"se referem a expectativas que podem ser frustradas ou desencorajadas". Concomitante à confiança, existe uma perspectiva de risco sempre mais ou menos previsível de acordo com o modo de estruturação das relações em certo espaço social. A confiança na vida cotidiana e nas relações com pessoas que partilham de um mesmo lugar de moradia, por exemplo, expressa uma familiaridade que não perde a dimensão das possibilidades dos riscos, pois se presume que certos acontecimentos inconvenientes à pessoa possam ou não suceder no decorrer de um dia. Ademais, as relações de confiança em um espaço social, como um bairro urbano, formam um sistema simbólico de relações de trocas e de posições que, no caso da periferia, parecem variar de acordo com o status quo da pessoa. Assim, observamos que as formas de reconhecimento implicam criações de fronteiras e separações entre sujeitos que se movem e confiam cada vez menos nas possibilidades de os outros se comportarem como devem e de os governos realizarem seu papel de controlar o crime e preservar os direitos de cidadania constitutivos do Estado democrático de direito que integram.

\section{Considerações finais}

Os ecos da violência produzem significativas mudanças sociais na estruturação da cidadania e, portanto, na dinâmica da vida em uma democracia afetada por situações que escapam ao monopólio da violência legítima pelo Estado. As condições de vida e a capacidade de governo são recorrentemente lembradas como problemáticas, refletindo problemas sociais do dia a dia. Os efeitos políticos desse fenômeno atingem as relações entre os moradores da periferia ao causar, entre outras coisas, repercussões diferenciadas no seu modo de agir e se relacionar com instituições que compõem a esfera pública nos bairros e cidades onde vivem. Diante da difusão dos crimes, da incapacidade do Estado de promover a garantia da segurança pública e do aumento da perspectiva de ser vítima da violência urbana, os moradores urbanos criam estratégias e táticas para se antecipar ao risco (Peralva, 2000). Os moradores destacaram a segurança pública como uma das principais reivindicações pertinentes às lutas por melhores condições de vida nos seus locais de moradia. A perda de confiança na gestão do monopólio da violência legítima abriu possibilidades para que cada um pense em gerir sua própria segurança nas margens de uma democracia das diferenças entre diferentes.

Em linhas gerais, o Estado brasileiro, nas últimas duas décadas do século XX, não conseguiu produzir um sistema de segurança pública capaz de lidar com as novas configurações da violência urbana, principalmente nas periferias das grandes cidades, tornando os bairros de residência da população com menor poder aquisitivo os lugares privilegiados de atividades criminosas (Adorno, 2002). Ao refletir sobre a violência no Brasil, Chesnais (1999) destaca a existência de uma crise na capacidade do Estado democrático brasileiro em sua tarefa de ser representante do bem comum e repositório legítimo do direito e da força em nome do respeito. Destarte, as consequências do processo de expansão da criminalidade sentido pelos moradores das

11 Estas questões foram analisadas em pesquisa na cidade de Fortaleza sobre as incertezas relacionadas ao trabalho do sistema de justiça criminal cearense (Freitas et al., 1999).

12 Habermas (2012) se debruçou cuidadosamente sobre como o entendimento é construído na perspectiva do agir comunicativo de sujeitos que partilham intersubjetivamente de referenciais de entendimento. 
periferias urbanas, como os dos bairros investigados, se inscrevem no rol de debilitações pertencentes ao processo de formação de um Estado que se desenvolveu economicamente, redistribuiu direitos políticos, mas não superou fortes desigualdades econômicas e culturais no seu interior. É importante destacar que Silva (1999) critica a explicação focada na "crise do Estado", por se tratar, segundo ele, de apenas uma das dimensões dos problemas, muitas vezes apontada como a causa, desmotivando os pesquisadores a avaliar outras variáveis, como o crescimento do crime organizado nas áreas onde políticas substantivas do Estado não conseguiram ser efetivas. Então, a crise político-institucional seria apenas o centro nevrálgico dos problemas, ficando a cargo das pesquisas sociais a descoberta de variáveis possíveis do diálogo com esta linha de pensamento.

Por fim, consideramos importante a disposição de pesquisadores para adentrar cotidianos que refletem problemas práticos relacionados às formas es truturantes das relações entre sujeitos de direito e Estado democrático, explorando seus intercâmbios em territórios que estão às margens dos centros de decisão dos gover- nos. Ao compreender a periferia como um problema, os responsáveis pela gestão pública adotam medidas reativas, investindo em intervenções que operam nos registros criados pelos ecos da violência. As forças policiais, por exemplo, adotam medidas reativas fundamentadas em referências morais construídas no interior da própria periferia, elegendo os que devem ser protegidos e os que devem ser enfrentados. O cotidiano, não poucas vezes, é representado como uma "guerra" na qual todos perdem em consequência de problemas que são resultados de intervenções caóticas cada vez mais incisivas e menos democráticas. Criam-se zonas nas quais ações arbitrárias, soluções violentas e abusos de autoridade são comuns. As "soluções" são resultados de escolhas particulares, e o Estado como projeto político se torna uma entidade policial, com impactos decisivos na vida de quem vive na periferia. As fronteiras e diferenciações criadas impedem uma reflexão coletiva sobre as condições que tornam possíveis as reproduções de práticas de violência, tornando a própria violência o caminho pelo qual a democracia se constitui no cotidiano de moradores afetados pelas suas múltiplas formas de manifestação e enunciação.

\section{Referências}

ADORNO, Sergio. Exclusão socioeconômica e violência urbana. Sociologias, v. 4, n. 8, p. 84-135, 2002.

AGAMBEN, Giorgio. Estado de exceção. São Paulo: Boitempo, 2004.

AVRITZER, Leonardo; COSTA, Sérgio. Teoria crítica, democracia e esfera pública: concepções e usos na América Latina. Dados, v. 47, n. 4, p. 703-728, 2004.

BARREIRA, César. Em nome da lei e da ordem: a propósito da política de segurança pública. São Paulo em Perspectiva, v. 18, n. 1, p. 77-86, 2004.

BAUMAN, Zygmunt. Comunidade: a busca por segurança no mundo atual. Rio de janeiro: Jorge Zahar Editor, 2003.

BEATO F., Claudio C. Determinantes da criminalidade em Minas Gerais. Revista Brasileira de Ciências Sociais, v. 13, n. 37, p. 74-87, 1998.

BRICEÑO-LEÓN, Roberto. La nueva violencia urbana de América Latina. In: BRICEÑO-LEÓN, Roberto. Violencia, sociedad y justicia en América Latina. Buenos Aires: CLACSO, 2002.

CALDEIRA, Teresa Pires do R. Cidade de muros: crime, segregação e cidadania em São Paulo. São Paulo: Editora 34, 2003.

CHESNAIS, J. C. A violência no Brasil. Causas e recomendações políticas para sua prevenção. Ciências E Saúde Coletiva, v. 4, n. 1, p. 53-69, 1999.

DAS, Veena. Life and word. In: DAS, Veena. Violence and the descent into the ordinary. Berkeley: University of California Press, 2006.

. En la región del rumor. In: ORTEGA, Francisco A (ed.). Veena Das: sujetos del dolor, agentes de dignidade. Bogotá:
Universidad Nacional de Colombia, Pontificia Universidad Javeriana e Instituto Pensar, 2008.

DAS, Veena; POOLE, Deborah. El Estado y sus márgenes: etnografias comparadas. Cuadernos de Antropología Social, n. 27, p. 19-52, 2008.

FELTRAN, Gabriel de S. Margens da política, fronteiras da violência: uma ação coletiva das periferias de São Paulo. Lua Nova, v. 79, p. 201-233, 2010.

FREITAS, Geovani Jacó de. Ecos da violência. Rio de Janeiro: Relume Dumará, 2003.

FREITAS, Geovane Jacó de; BARREIRA, César; ABREU, Domingos Sávio; SÁ, Leonardo Damasceno de; et al. À espera de justiça: assassinato de crianças e adolescentes na Grande Fortaleza. Fortaleza: Expressão, 1999.

GIDDENS, Anthony. As consequências da modernidade. São Paulo: Editora UNESP, 1991.

GLASSNER, Barry. Cultura do medo: por que tememos cada vez mais o que deveríamos temer cada vez menos. São Paulo: Francis, 2003.

HABERMAS, Jürgen. Teoria do agir comunicativo: sobre a crítica da razão funcionalista. São Paulo:WMF Martins Fontes, 2012. HOLSTON, James. Cidadania insurgente: disjunções da democracia e da modernidade no Brasil. São Paulo: Companhia das Letras, 2013.

MACHADO, Eduardo Paes; NORONHA, CeciVilar. A polícia dos pobres: violência policial em classes populares urbanas. Sociologias, v. 4, n. 7, p. 188-221, 2002.

MISSE, Michel. Sobre a construção social do crime no Brasil. In: MISSE, Michel. Acusados e acusadores: estudos sobre ofensas, 
acusações e incriminações. Rio de Janeiro: Revan, 2008.

Crime, sujeito e sujeição criminal: aspectos de uma contribuição analítica sobre a categoria “bandido". Lua Nova, v. 79 , p. 15-38, 2010.

NETO, Plinio Leitão. Conjunto Ceará: polo de desenvolvimento. Fortaleza: PRODECOM, 1999.

NIETZSCHE, Friedrich. Humano, demasiado humano: um livro para espíritos livres. São Paulo: Companhia das Letras, 2000. O'DONNELL, Guillermo. Notas sobre la democracia en América Latina. In: Programa de las Naciones Unidas para el Desarrollo. La democracia en América Latina: hacia una democracia de ciudadanas y ciudadanos. Buenos Aires: Aguilar, Altea, Taurus, Alfaguara, 2004.

PAIVA, Luiz Fábio S. Contingências da violência em um território estigmatizado. Campinas: Pontes, 2014.

PERALVA, Angelina. Violência e democracia: o paradoxo brasileiro. São Paulo: Paz e Terra, 2000.

ROSANVALLON, Pierre. Las dimensiones social y nacional de la democracia: hacia un marco de comprensión ampliada. In: Programa de las Naciones Unidas para el Desarrollo. La democracia en América Latina: hacia una democracia de ciudadanas y ciudadanos. Buenos Aires: Aguilar, Altea, Taurus, Alfaguara, 2004.

SILVA, Luiz Antônio Machado da. Criminalidade violenta: por uma nova perspectiva de análise. Revista de Sociologia e Política, n. 13, p. 115-124, 1999.

.(org.). Vida sob cerco: violência e rotina nas favelas do Rio de Janeiro. Rio de Janeiro: Nova Fronteira, 2008.
SILVA, Luiz Antônio Machado da; LEITE, Márcia Pereira. Violência, crime e polícia: o que os favelados dizem quando falam desses temas? Sociedade e Estado, v. 22, n. 3, p. 545-591, 2007.

SKOGAN, Wesley. Fear of crime and neighborhood change. Crime and Justice, v. 8, p. 203-229, 1986.

SOUZA, Jessé. A construção social da subcidadania: para uma sociologia política da modernidade periférica. Belo Horizonte: Editora UFMG, 2012.

SANTOS, José Vicente Tavares dos. Novos processos sociais globais e violência. São Paulo em Perspectiva, v. 13, n. 3, p. 18 23, 1999.

TILLY, Charles. Democracia. Petrópolis: Editora Vozes, 2013.

VELHO, Gilberto. Cidadania e violência. Rio de Janeiro: Editora UFRJ, 1996.

WARR, Mark. Fear of crime in the United States: avenues for research and policy. Criminal Justice, v. 4, n. 4, p. 451-489, 2000.

WEBER, Max. Economia e sociedade: fundamentos da sociologia compreensiva. Volume 2. Brasília e São Paulo: Editora UnB e Imprensa Oficial de São Paulo, 1999.

A ética protestante e o "espírito" do capitalismo. São Paulo: Companhia das Letras, 2004.

ZALUAR, Alba. Integração perversa: pobreza e tráfico de drogas. Rio de Janeiro: Editora FGV, 2004.

.A máquina e a revolta: as organizações populares e o significado da pobreza. São Paulo: Brasiliense, 1985.

\title{
Echoes of violence on the margins of a democratic society: the case of the outskirts of Fortaleza
}

\begin{abstract}
:
This article is the result of ethnographic research conducted in neighborhoods located on the outskirts of Fortaleza (CE), Brazil. Such investigations aimed to understand the everyday and political effects of violence in urban areas. We note that violence in the outskirts can be interpreted from the echoes produced in the social life of individuals who, in theory, should be safeguarded by constitutive instances of a democratic society of rights. In order to understand this, we want to know how people interpret and speak of violence in the neighborhoods where they live. We found echoes of violence that can be perceived in rumors, fears and separations created in the communities where we have researched. Such effects reverberate in how people interpret their actions in a democracy, sharing rights and duties to people who do not recognize themselves as equals. Generally speaking, citizenship is conceived here as a structural problem of moral life in the outskirts.
\end{abstract}

Key words: violence; democracy; citizenship; fear; outskirts.

\section{Ecos de la violencia en las márgenes de una sociedad democrática: el caso de la periferia de Fortaleza}

\section{Resumen:}

El trabajo es el resultado de las investigaciones etnográficas realizadas en los barrios ubicados en la periferia de Fortaleza (CE). Estas investigaciones tuvieron como objetivo comprender efectos cotidianos y políticos de la violencia en territorios urbanos. Observamos que, además 
de la experiencia empírica, la violencia en la periferia se puede interpretar a partir de los ecos producidos en la vida social de las personas que, en teoría, deberían estar protegidas por instancias constitutivas de una sociedad democrática de derecho. Para que esto sea comprendido, buscamos saber cómo las personas interpretan y hablan de la violencia en los barrios donde viven. Encontramos ecos de la violencia que se pueden percibir en rumores, miedos y separaciones creadas en las comunidades analizadas. Sus efectos reverberan en la forma como las personas interpretan sus acciones en una democracia, compartiendo derechos y deberes con personas que no se reconocen como iguales. En términos generales, la ciudadanía se concibe aquí como un problema moral estructurante de la vida en la periferia.

Palabras clave: violencia; democracia; ciudadanía; miedo; periferia. 